\title{
Water catchment with native species in the Brazilian Semiarid
}

\author{
João Vianey Fernandes Pimentel ${ }^{1}$, Hugo Orlando Carvallo Guerra ${ }^{2}$, \\ Francisco Jardel Rodrigues da Paixão ${ }^{3}$, Luciano F. Marques ${ }^{4}$, Leandro do Vale ${ }^{4}$, \\ Francisca N. Brito ${ }^{5}$
}

\footnotetext{
${ }^{1}$ Agroecology and Environment of Federal Institute of Education Science and Technology of Rio Grande do Norte (UFRN), Quixeramobim, Brazil; vianeypim@gmail.com

${ }^{2}$ Agricultural Engineering, Department of Graduate Agricultural Engineering, Federal University of Campina Grande (DEAG/ UFCG), Campina Grande, Brazil

${ }^{3}$ Technological Axis Natural Resources Centec Institute/Fatec Sertão Central, Quixeramobim, Brazil;

Jardel.paixao@gmail.com, Jardel@centec.org.br

${ }^{4}$ State University of Maranhão (UEMA), Balsas, Brazil

${ }^{5}$ Agribusiness Centec Institute/FATEC Sertão Central, Undergraduate Scholarship Foundation Protection Research of Ceará, FUNCAP, Quixeramobim, Brazil
}

Received 26 November 2013; revised 18 January 2014; accepted 29 January 2014

Copyright (C) 2014 João Vianey Fernandes Pimentel et al. This is an open access article distributed under the Creative Commons Attribution License, which permits unrestricted use, distribution, and reproduction in any medium, provided the original work is properly cited. In accordance of the Creative Commons Attribution License all Copyrights @ 2014 are reserved for SCIRP and the owner of the intellectual property João Vianey Fernandes Pimentel et al. All Copyright (C) 2014 are guarded by law and by SCIRP as a guardian.

\section{ABSTRACT}

Xerophyticplants are well adapted to the semiarid conditions because they have a high potential for the use of rainwater. They can store it in their roots (xylopodiums). The Amburanacearensis, commonly called Cumaru, native of the Brazilian semiarid, is very important because of its multiple-use: good quality wood, active food ingredient, perfume and medicine production. However, its management is practically unknown. Aiming to know more about this culture, an experiment was conducted to quantify the Cumaruwater needs, evaluate its water-use efficiency and the capacity of roots to store water. Five levels of water $(0 \%, 25 \%, 50 \%, 75 \%$ and $100 \%$ of evapotranspiration) and five-plant spacing $(0.20 \times$ $0.20 \mathrm{~m}, 0.20 \times 0.10 \mathrm{~m}, 0.20 \times 0.05 \mathrm{~m}, 0.10 \times 0.10 \mathrm{~m}$ and $0.05 \times 0.05 \mathrm{~m}$ ) were tested, and the results obtained analyzed statistically throughout $F$ test. No influence of soil water level and plant spacing in the moisture content of the whole plant, in the aerial part or in the xylopodiums was observed. However, there was an effect of the treatments on the water stored in the whole plant in the aerial part or in the roots, per unit area. More than $80 \%$ of the water was stored in the roots. The crop growing with the smaller spacing without irrigation was shown to be quite efficient in using the rainwater, compared with traditional cultures irrigated.

\section{KEYWORDS}

\section{Xerophytic; Xylopodium; Semiarid; Water Use Efficient}

\section{INTRODUCTION}

Duke states that one of the ways to resist the pauperism in the semiarid regions is to eliminate the uncertainness of annual tillage due to the periodic wet and dry weather conditions, thus giving the farmer a safe agricultural based on the use of drought-resistant plants which provides food for the creation of cattle with plenty of fodders, and way of life more methodical. The use of xerophytes, particularly those presenting xylopodiums, seems to offer an adequate alternative for the agriculture.

Gnadlinger [2] indicates that xerophyliticplants of the caatinga region ("White Wood") are well adapted to dry conditions. They are leafless and take a white coloration during the dry season to reduce water losses through transpiration. Cacti, Umbutree (Spatodiatuberosa), Juazeiro (Zizyphusjoazeiro), Waxpalm (Coperniciacerifera) and many other xerophyliticspecies have their own mechanisms of water absorption and storage and prevention 
against perspiration losses. The roots of the cactus, for example, near the surface, absorb rain water quickly; Umbu trees store water in the roots (until 2500 $\mathrm{kg} /$ tree). Duke [3] confirms that the roots of droughtresistant plants have an anatomy and physiology rigorously synchronized with the ecology of the region and they are much more important as the organs that were considered.

The Amburanacearensis also known as cumaru, a native plant of multiple uses with its good quality timber, easy to work with and pleasant aroma, is sold comercially under the name Cherry. Its roots (xilopódios), bark and seeds, produce coumarin, active principle which, apart from being used in food industries (candies and cookies), cigarettes and tobacco, perfume industries as fixative is also used in the production of drugs such as the Cumaru syrup or homemade lickers, of broad popular use, proven scientifically as anti-inflammatory and bronchodilator [4]. For its beauty, the tree can be used as ornamental landscape projects. For the soil recovery and the restoration of degraded environments, it is used both at the initial and the later stages of reforestation, even as riparian vegetation in areas with periodic and short duration floodings [5]. In agroforestry systems, the cumaru can be used as windbreaks and tracks on tree plantations. As forage, its leaves and pods are eaten by goats, both green and dry, and by the cattle after drying. It is also of great importance for beekeeping and meliponiculture, providing nectar in the dry season, ranking among the 18 most used species by native bees for pollen and/or nectar and as nesting sites, besides the use of its wood in the construction of hives [6].

It already studies the possibility of plant cultivation in flower beds to produce herbals of broad popular use. Canuto [4] indicates that young plants, from 7 months old, may replace the mature plants husks, reducing the risk of extinction by vegetation exploitation.

Considering that most of the rain water in the semiarid is lost without any productive use, the cultivation of native species, especially those that store water in the xylopodiums, constitutes an alternative to capture the water, contributing to human sustainability. The objective of this study, thus, was to quantify the water needs of Cumaru in flower beds, determining how much of this water is stored in the xilopodiums and its water-use efficiency.

\section{MATERIAL AND METHODS}

The experiment was conducted at the Center for Environmental Education (NEA), of the Brazilian Institute of Environment (IBAMA), at Quixeramobim, one of the largest municipalities of Central Ceará State, with an area of $3275 \mathrm{~km}^{2}$. It is located in the semiarid region, with geographic coordinates with 5th 12'08" south latitude, $39^{\circ} 17^{\prime} 11^{\prime \prime}$ west longitude and altitude of $196 \mathrm{~m}$ above sea level, 204 km from Fortaleza, capital of Ceará. According to IBGE [7], the total population was 71,887 inhabitants, including rural and urban areas. The municipality of Quixeramobim presents prevalence of soils Bruno No Calcite (37.4\%), Planossolo Solodic (34.7\%), Litholic (9.6\%), Brunizem Reddish (8.8\%), Red-Yellow Podzolic (6.6\%), Vertisol (2.4\%) and Regossolo (0.5\%), Bruno No Calcite (37.4\%), Planossolo Solodic (34.7\%), Litholic (9.6\%), Brunizem Reddish (8.8\%), Red-Yellow Podzolic (6.6\%), Vertisol (2.4\%) and Regossolo (0.5\%), with slopes of $0 \%$ - 5\%. The climate, according to Köppen classification, is the type BShw'-semiarid with short rainy season in summer-autumn, with concentration of rainfall in the months of March and April. The normal average rainfall of the municipality is $708.5 \mathrm{~mm}$ [8]. The average temperature ranges between $22.8^{\circ} \mathrm{C}$ and $32.5^{\circ} \mathrm{C}$. The main water resources are the Fogareiro reservoir with a capacity of $118,820,000 \mathrm{~m}^{3}$, perpetuating the river and the Quixeramobimdam with a capacity of 54,000,000 $\mathrm{m}^{3}$, in addition to various public and private dams of medium and small size, without counting the lakes and groundwater reserves of crystalline aquifers.

Five flowerbeds $1 \mathrm{~m}$ wide, $15 \mathrm{~m}$ long, and $40 \mathrm{~cm}$ height were excavated, internally lined with plastic sheeting to a depth of $20 \mathrm{~cm}$ and filled with a mix of soil and manure in ratio of 100 liters of manure per square meter of bed, corresponding to the proportion of $25 \%$ by volume. Planting took place with two seeds per hill plot, according to the spacing provided for each treatment.

Five water contents were tested: 0\%, 25\%, 50\%, 75\% and $100 \%$ of the evapotranspiration. The $0 \%$ treatment received only the natural precipitation. The other treatments were obtained complementing the precipitation with irrigation water supplied with three drip tapes with drips every $30 \mathrm{~cm}$. The flower bed was divided in five parcels of $1.0 \mathrm{~m}^{2}$ each one with a different spacing: 0.20 $\times 0.20 \mathrm{~m} ; 0.20 \times 0.10 \mathrm{~m} ; 0.20 \times 0.05 \mathrm{~m} ; 010 \times 0.10 \mathrm{~m}$ and $0.05 \times 0.05 \mathrm{~m}$.

After stabilization of the stand at 90 days (taking 30 days to complete germination of all seeds and the remainder to reach uniformity), with thinning and replanting of plants the biometry was conducted collecting monthly a plant for square meter, in which the total, roots and aerial fresh weight and the total, root and shoot dry matter weight were measured. In the present work, only the data obtained at the end of the experiment (210 DAS) is presented. The experiment was conducted in the period from January to August 2010.

During the experimental period, from January to August 2010, the monthly precipitation registered in the area was: 


\begin{tabular}{cc}
\hline Month & Precipitation $(\mathbf{m m})$ \\
\hline January & 76.0 \\
February & 19.0 \\
March & 8.5 \\
April & 235.0 \\
May & 62.5 \\
June & 133.0 \\
July & 0.0 \\
August & 0.0 \\
Total & $\mathbf{6 1 3 . 0}$ \\
\hline
\end{tabular}

The evapotranspiration used was the actual or real, determinated by the water consumption of the plant in the flowerbeds that received an irrigation depth of $100 \%$ of the evapotranspiration (Treatment I5), subtracting the drained from the applied water, a day before the irrigation.

The total fresh weight, roots and aerial part was measured on a balance with a scale accuracy of $0.1 \mathrm{~g}$. For the determination of dry matter, the parts of the plant, total, root and shoot were placed in paper bags, dried in a oven with controlled temperature of $65^{\circ} \mathrm{C}$ for 24 hours and weighed on a balance with a scale accuracy of $0.1 \mathrm{~g}$.

The moisture content was determined by the ratio beween the difference of fresh and dry weights and fresh t weight, multiplied by one hundred, (fresh-dry/fresh) $\times$ 100 . The moisture content in each plant per square meter of flowerbed, was obtained multiplying the moisture content of the fresh plant weight by the number of plants per square meter.

The water use efficiency was determined using the relationship between the total cumaru fresh weight produced and the amount of water consumed per $\mathrm{m}^{2}$, expressed in $\mathrm{g} \cdot \mathrm{L}^{-1}$.

The statistical design was a randomized block, split plot distributed, with five water levels (I1 = precipitation only; I2 = precipitation + irrigation to reach $25 \%$ of ET; $\mathrm{I} 3=$ precipitation + irrigation to reach $50 \%$ of ET; I4 = precipitation + irrigation to reach $75 \%$ of ET and $\mathrm{I} 5=$ precipitation + irrigation to reach $100 \%$ of ET) and five spacings $(\mathrm{S} 1=0.20 \times 0.20 \mathrm{~m}, \mathrm{~S} 2: 0.20 \times 0.10 \mathrm{~m}$; S3: $0.20 \times 0,0.5 \mathrm{~m}$; S4: $0.10 \times 0.10 \mathrm{~m}$, and S5: $0.05 \times 0.05$ $\mathrm{m})$ and three replications, totalizing 75 plots.

The effects of treatments were assessed by variance and regression analysis, using the software SISVAR, DEX/ UFLA [9].

\section{RESULTS AND DISCUSSION}

It is observed on Table 1 that there was no significant

Table 1. Analysis of variance and means for the moisture in the whole plant (\% UT), in the xilopódios (UX\%), in the aerial part (UPA\%) and water content in the whole plant (CAP), in the xylopodiums (CAX) and in the aerial part (CAPA), with respect to the water applied (I) and plant spacing (S) in young plants of Cumaru, 210 days after sowing, Quixeramobim, CE, 2010.

\begin{tabular}{|c|c|c|c|c|c|c|c|}
\hline \multirow[t]{2}{*}{ F.V. } & \multirow[t]{2}{*}{ G.L. } & \multicolumn{6}{|c|}{ Medium squares } \\
\hline & & $\%$ UT & $\%$ UX & \% UPA & CAP & CAX & CAPA \\
\hline Water (I) & 4 & $18.99 \mathrm{~ns}$ & $31.83 \mathrm{~ns}$ & $69.80 \mathrm{~ns}$ & $0.19 \mathrm{~ns}$ & $0.11 \mathrm{~ns}$ & $0.03 \mathrm{~ns}$ \\
\hline Spacing (S) & 4 & $113.87 \mathrm{~ns}$ & $41.78 \mathrm{~ns}$ & $70.20 \mathrm{~ns}$ & $1.37^{* *}$ & $1.09^{* *}$ & $0.08^{*}$ \\
\hline - Linear regression & 1 & & & & $55.80^{* *}$ & $42.41^{* *}$ & $0.24^{* *}$ \\
\hline - Quadratic regression & 1 & & & & $2.60 \mathrm{~ns}$ & $3.37 \mathrm{~ns}$ & $0.00 \mathrm{~ns}$ \\
\hline Water $\times$ Spacing $(I x ~ S)$ & 16 & $73.06 \mathrm{~ns}$ & $53.73 \mathrm{~ns}$ & $152.96 \mathrm{~ns}$ & $0.19 \mathrm{~ns}$ & $0.15 \mathrm{~ns}$ & $0.03 \mathrm{~ns}$ \\
\hline Blocks & 2 & $144.98 \mathrm{~ns}$ & $86.43 \mathrm{~ns}$ & $509.99 \mathrm{~ns}$ & $0.51 \mathrm{~ns}$ & $0.42 \mathrm{~ns}$ & $0.03 \mathrm{~ns}$ \\
\hline CV(\%) (water) & & 9.21 & 7.00 & 18.52 & 25.58 & 22.77 & 13.19 \\
\hline CV(\%) (spacing) & & 9.40 & 8.85 & 9.51 & 15.30 & 14.58 & 11.58 \\
\hline CV(\%) (interaction) & & 10.74 & 9.81 & 15.78 & 25.23 & 22.97 & 14.52 \\
\hline \multirow[t]{3}{*}{ Water applied (I) } & & \multicolumn{6}{|c|}{ Mean without transformation } \\
\hline & UT & $\mathbf{U X}$ & & & CAP & CAX & CAPA \\
\hline & $(\%)$ & $(\%)$ & & & $\left(\mathbf{L} \cdot \mathbf{m}^{-2}\right)$ & $\left(\mathbf{L} \cdot \mathbf{m}^{-2}\right)$ & $\left(\mathbf{L} \cdot \mathbf{m}^{-2}\right)$ \\
\hline $\mathrm{I} 1(0.00 \mathrm{ET})$ & 74.25 & 77.10 & & & 1.24 & 1.11 & 0.15 \\
\hline $\mathrm{I} 2(0.25 \mathrm{ET})$ & 73.26 & 77.13 & & & 1.21 & 1.07 & 0.16 \\
\hline $\mathrm{I} 3(0.50 \mathrm{ET})$ & 76.06 & 77.88 & & & 2.18 & 1.74 & 0.46 \\
\hline $\mathrm{I} 4(0.75 \mathrm{ET})$ & 73.34 & 80.55 & & & 1.15 & 1.06 & 0.14 \\
\hline I5(1.00 ET) & 74.25 & 77.35 & & & 1.59 & 1.29 & 0.31 \\
\hline \multicolumn{8}{|l|}{ Spacing (S) } \\
\hline $\mathrm{S} 1(0.20 \times 0.20 \mathrm{~m})$ & 76.88 & 80.72 & & & 0.45 & 0.39 & 0.06 \\
\hline $\mathrm{S} 2(0.20 \times 0.10 \mathrm{~m})$ & 70.06 & 76.40 & & & 0.65 & 0.59 & 0.08 \\
\hline S3 $(0.20 \times 0.05 \mathrm{~m})$ & 75.23 & 77,55 & & & 1.72 & 1.33 & 0.41 \\
\hline $\mathrm{S} 4(0.10 \times 0.10 \mathrm{~m})$ & 76.04 & 78.30 & & & 1.45 & 1.23 & 0.23 \\
\hline $\mathrm{S} 5(0.05 \times 0.05 \mathrm{~m})$ & 72.94 & 77.06 & & & 3.10 & 2.74 & 0.44 \\
\hline
\end{tabular}

\footnotetext{
** Significant at the $1 \%$ level of probability $(\mathrm{p}<0.01)$; "Significant at $5 \%$ level of probability $(\mathrm{p}<0.05)$; ns: not significant.
} 
effect of the water levels, or the plant spacing or the interaction on the moisture content of the whole plant, xilophodiumor aerial part of the young plants of Cumaru beds, at 210 days after sowing. This indicates that the Cumaruis a rustic plant, adapted to low soil water contentconditions, and that supplementary irrigation does not increase the moisture content of the plant, even in the water reserve organs (xylopodiums).

Chaves Filho \& Stacciarini-Seraphin [10] studying a savannah native specie, Solanumlycocarpum (commonly known as lobeira), found no difference in relative water content of leaves when submitted to water stress treatments. However, they claim that it cannot be conclude that these plants are in fact insensitive to marked dehydration of the upper layers of the soil during the dry season. Everything indicates that these plants are physiologically adapted to the conditions of "dry season" invariably associated to the existence of savannas, as the “caatinga”. Fahn \& Cutler [11] said that plants, established from the beginning in environments with restricted water availability developed anatomic and physiological adaptations, which resulted in the adaptation success to the hostile conditions of water that these environments offer.

The water content of plants per square meter of bed for the whole plants, xylopodiums and shoots was not affected by the soil water content; however it was significantly affected by plant spacing (Table 1). Obviously, as the spacing among plants decrease, the number of plants per square meter increases, increasing also the water catch per unit area. Table 1 shows that, as the culture become denser, the uptake of water per square meterincreased, capturing $3.10 \mathrm{~L} \cdot \mathrm{m}^{-2}$ of bed with the shortest plant spacing tested $(0.05 \times 0.05 \mathrm{~m})$ compared with the $0.45 \mathrm{~L} \cdot \mathrm{m}^{-2}$ with the plant spacing of $0.20 \times 0.20 \mathrm{~m}$. It is apparent that between S3 and S4 treatments the results were similar, because even though they are two different spatial arrangements $(0.20 \times 0.05 \mathrm{~m}$ and $0.10 \times 0.10 \mathrm{~m})$, the area is the same $\left(0.01 \mathrm{~m}^{2}\right)$. Approximately $88.4 \%$ of the water was accumulated on the xylophodiums.

As there was not response of the cumaru to the irrigation, the water use efficiency was calculated only for the treatment that not received irrigation (0.00 ET) and only received rainwater. Similarly, as the most adequate spacing recommended from Pimentel [12] was the densest, it was considered only the treatment S5 $(0.05 \times 0.05$ $\mathrm{m})$.For this treatment, the water-use efficiency obtained was For this treatment, the water-use efficiency obtained was $10.02 \mathrm{~g} \cdot \mathrm{L}^{-1}$. The water-use efficiency obtained in the present study is superior to those found on the references. Silva et al. [13] indicate that cultures with great efficiency in water use, such as irrigated sugarcane forage has indexes of $1.67 \mathrm{~g} \cdot \mathrm{L}^{-1}$. Barros Júnior et al. [14] obtained in treatments with $100 \%$ of available water in the soil, water efficiency index of $2.80 \mathrm{~g} \cdot \mathrm{L}^{-1}$ for castor beans, considered a water resistant crop. The rosemary-pepper, traditional medicinal plant in the semiarid that produces an essential oil, had a water use efficiency of $1.26 \mathrm{~g} \cdot \mathrm{L}^{-1}$ with an irrigation depth of 1.65 of the reference evapotranspiration [15].

Attention should be paid that, the cumaru, with seven months, has the potential to be fully used (root, stem and leaves) in the pharmaceutical industry. Because, at this age, it already contains the active principles in all parts [4]. It can be supplied, fresh, directly by the farmer since the moisture content for the manipulation (between 8 and $14 \%$ ) can be obtained by the proper pharmaceutical industry.

\section{CONCLUSIONS}

1) The moisture content in the whole plant, in xylopodiums and aerial part of the plant, cultivated in flower beds, were indifferent to the use of supplementary irrigation and spacing.

2) The water content of the whole plant, xylophodiums and aerial part of the plant per $\mathrm{m}^{2}$ of bed was not influenced by the soil water content, however, increased with the decrease of plant spacing which meant increase of plants per $\mathrm{m}^{2}$.

3) The highest water use efficiency was obtained with the lowest plant spacing.

4) It is recommended that further studies will be conducted with the use of native plants in the semiarid. Besides the socioeconomically importance, they are a great alternative to use the scarce water resources in this region, ensuring thus the ecological sustainability.

\section{REFERENCES}

[1] Duke, J.G. (2004) The Northeast and crops xerófilas. 4th Edition, Bank of Northeast of Brazil, Fortaleza.

[2] Gnadlinger, J. (2003) Catchment and management of rainwater and sustainable development of semi-arid Brazil-An integrated vision. 4th Brazilian Symposium on Capture and Management Rainwater, Petrolina, July 2003.

[3] Duke, J.G. (2004) Soil and water in the drought polygon. 6th Edition, Bank of Northeast of Brazil, Fortaleza.

[4] Canuto, K.M. (2007) Chemical aspects of the interdisciplinary study (agronomy chemistry-pharmacology) of Amburanacearensis A. C. Smith. 313 f. Ph.D. Thesis, Federal University of Ceará, Fortaleza.

[5] Maia, G.N. (2004) Caatinga: Trees and shrubs and their utilities. Reading and Art, Sao Paulo.

[6] Marine, I.V., Freitas, M.F., Zanella, F.C.V., Caldas, A.L. (2002) Plant species of Caatinga used by indigenous stingless bees as font of resources and nesting place. 1st Brazilian Congress of University Extension, University Press, Joao Pessoa. 
[7] Brazilian Institute of Geography and Statistics (IBGE) (2010) Synopsis of the demographic census. http://www.censo2010.ibge.gov.br/sinopse/index.php?uf= 23\&dados $=1$

[8] Cearense Foundation of Meteorology and Resources Hydric (1988) Bulletin climatic monitoring. FUNCEME, Fortaleza.

[9] Ferreira, D.F. (2007) Sisvar version 5.0. System of statistical analysis. UFLA, Mines.

[10] Chaves Filho, J.T. and Stacciarini-Seraphin, E. (2012) Alteration in osmotic potential and soluble carbohydrates content in young plants of lobeira (Solanumlycocarpum St.-Hil.) in response to water stress. http://www.scielo.br/scielo.php?script=sci_arttext\&pid=S 0100-84042001000200010\&lng=en\&nrm=iso

[11] Fahn, A. and Cutler, D. (1992) Xerophytes. Gebruder Born- traeger, Berlin.

[12] Pimentel, J.V.F. (2011) Growing cumaru (Amburanacearensis) in different production systems in the semiarid. Ph.D. Thesis, Federal University of Campina Grande, Campina Grande.

[13] Silva, G. and Thieres, F., et al. (2011) Hydric demand and water use efficiency of sugar cane in the Brazilian semiarid irrigated. Rev. bras. eng. agric. ambient., Campina Grande.

[14] Barros Jr., G., et al. (2008) Water consumption and use efficiency for two castor bean cultivars under hydric stress. Rev. bras. eng. agric. ambient., Campina Grande.

[15] Lopes, O.D., et al. (2011) Determination of crop coefficient $(\mathrm{Kc})$ and water use efficiency of irrigated rosemary pepper. Rev. bras. eng. agric. ambient., 15, 1415-4366. 